\title{
Effect of dietary lipid structure in early postnatal life on mouse adipose tissue development and function in adulthood
}

\author{
Annemarie Oosting ${ }^{1 *}$, Naomi van Vlies ${ }^{2} \dagger$, Diane Kegler ${ }^{1}$, Lidewij Schipper ${ }^{1}$, \\ Marieke Abrahamse-Berkeveld ${ }^{1}$, Silvia Ringler ${ }^{1}$, Henkjan J. Verkade ${ }^{3}$ and Eline M. van der Beek ${ }^{4}$ \\ ${ }^{1}$ Danone Research - Centre for Specialised Nutrition, Bosrandweg 20, 6704 PH, Wageningen, The Netherlands \\ ${ }^{2}$ Division of Pharmacology, Department of Pharmaceutical Sciences, Utrecht University, Utrecht, The Netherlands \\ ${ }^{3}$ Department of Pediatric Gastroenterology and Hepatology, Beatrix Children's Hospital, University Medical Center \\ Groningen, University of Groningen, Groningen, The Netherlands \\ ${ }^{4}$ Danone Research - Centre for Specialised Nutrition, Singapore, Singapore \\ (Submitted 8 October 2012 - Final revision received 29 May 2013 - Accepted 29 May 2013 - First published online 11 July 2013 )
}

\section{Abstract}

Obese individuals have more (hyperplastic) and larger (hypertrophic) adipocytes in their white adipose tissue (WAT) than normal-weight individuals. The difference in cell number emerges early in childhood, suggesting that this is a critical period for being susceptible to obesity. Breast-feeding has been shown to be protective against obesity, and we have previously shown in mice that the physical structure of lipids in human milk may contribute to this protective effect. In the present study, we investigated how differences in the physical structure of lipids in the early diet may modulate adipose tissue development. Male mice were fed a diet containing control infant milk formula (Control IMF; Danone Research) or Nuturis ${ }^{\circledR}$ (Concept IMF with large phospholipid-coated lipid droplets; Danone Research) from postnatal day (PN)16 to 42. Subsequently, mice were challenged with a moderate Western-style diet (WSD) until PN98, and body composition was monitored by dual-energy X-ray absorptiometry. Epididymal WAT was analysed for adipocyte size, number and gene expression of metabolic transcription factors. Early Concept IMF exposure reduced fat accumulation during the WSD challenge by $30 \%$ compared with the Control IMF. It reduced adipocyte size without affecting adipocyte number in adult mice. The Concept IMF decreased the expression of PPAR $\gamma$, CCAAT/enhancer-binding protein and retinoid X receptor $\alpha$ in WAT in adulthood, key regulators of metabolic activity. In conclusion, Concept IMF exposure in early life reduced susceptibility to obesity in adult life, by preventing adipocyte hypertrophia upon adult dietary challenge without affecting adipogenesis. These data emphasise the importance of the physical properties of dietary lipids in early life in obesity risk later in life.

\section{Key words: Nutritional programming: Obesity prevention: Dietary lipids: Infant nutrition}

The development of human white adipose tissue (WAT) starts in the third trimester of gestation and continues in postnatal life through the proliferation of preadipocytes and subsequent differentiation, resulting in mature adipocytes storing energy in the form of lipids ${ }^{(1)}$. Adipocyte number increases throughout childhood and adolescence to plateau and remain constant in adulthood ${ }^{(2,3)}$. Surprisingly, adult cell turnover is similar in obese and lean subjects, although adult obese subjects have more adipocytes compared with lean subjects. Interestingly, this difference in adipocyte number already emerges early in childhood, suggesting that this may be a critical period for WAT development and obesity risk ${ }^{(2,3)}$.
Comparable to human ontogeny, WAT development in rodents is initially driven by hyperplastic growth (increase in number) and subsequent hypertrophic growth (increase in cell size). When fed a standard chow, total cell number is established in rodents between 9 and 18 weeks of age ${ }^{(4-6)}$ whereas adipocyte size can increase until senescence ${ }^{(7)}$. Additionally, adipocyte size and number are higher in obese rats compared with lean rats ${ }^{(8)}$, and hyperplastic and hypertrophic growth dynamics differ according to fat depot, sex and $\operatorname{diet}^{(9,10)}$.

The growth of both hypertrophic and hyperplastic adipocytes is regulated by the concerted actions of several

\footnotetext{
Abbreviations: \%FM, percentage of fat mass; BW, body weight; CEBP, CCAAT/enhancer-binding protein; EPI, epididymal; FA, fatty acid; FM, fat mass; HDL-C, HDL-cholesterol; IMF, infant milk formula; ING, inguinal; LDL-C, LDL-cholesterol; PL, phospholipids; PN, postnatal day; RXR $\alpha$, retinoid X receptor $\alpha$; SREBP1C, sterol regulatory element-binding protein 1c; TC, total cholesterol; WAT, white adipose tissue; WSD, Western-style diet.
}

*Corresponding author: A. Oosting, fax +31 317466 500, email annemarie.oosting@danone.com

† Present address: Laboratory of Genetic Metabolic Disease, Academic Medical Center, University of Amsterdam, The Netherlands. 
transcription factors such as PPAR $\gamma$, retinoid $\mathrm{X}$ receptor $\alpha$ $(\mathrm{RXR} \alpha)$ and the CCAAT/enhancer-binding protein (CEBP) family members ${ }^{(11,12)}$. In vitro studies have shown that PPAR $\gamma$-deficient embryonic stem cells are unable to differentiate into adipocytes ${ }^{(13)}$. Additionally, overexpression of PPAR $\gamma$ in mature 3T3-L1 adipocytes reduces lipolysis and increases cell size and TAG content compared with control adipocytes. In contrast, a dominant-negative PPAR $\gamma$ mutant has the opposite effect of increasing lipolysis and reducing fatty acid (FA) uptake ${ }^{(14)}$. Data from human and mouse genetic studies have shown that the deletion of the WAT-specific PPAR $\gamma 2$ isomer reduces adipogenesis and impairs insulin sensitivity. Thus, PPAR $\gamma$ is clearly a key regulator to maintain lipid metabolic homeostasis. Many PUFA and lipid-derived mediators can act as endogenous PPAR $\gamma$ ligands ${ }^{(15)}$. This enables sensing of nutritional signals that can be translated into a metabolic response to maintain homeostasis.

Experimental studies have provided compelling evidence for the sustained effects of early-life nutrition on adipose tissue development and function. For instance, both maternal obesity and intra-uterine growth retardation induced by a $50 \%$ food-restricted diet in rats resulted in the up-regulation of PPAR $\gamma$, RXR $\alpha$ and CEBP family members in the offspring directly after birth, which was associated with increased adiposity during adulthood ${ }^{(16,17)}$. A clinical study investigating the obesogenic effect of a specific human PPAR $\gamma$ polymorphism has shown that breast-feeding is correlated with a lower BMI in adolescents carrying this polymorphism, suggesting that the protective effects of breast-feeding on the development of obesity are mediated, at least in part, via PPAR $\gamma^{(18)}$.

The protective effects of breast-feeding on obesity and metabolic health later in life are probably multifactorial ${ }^{(19)}$. One specific aspect is the fact that human milk contains large lipid droplets with an average mode diameter of $4 \mu \mathrm{m}$ surrounded by a native biological membrane composed of phospholipids (PL), proteins, enzymes, cholesterol and glycoproteins $^{(20)}$. In contrast, infant milk formula (IMF) contains small lipid droplets with an average mode diameter of $0.3-0.5 \mu \mathrm{m}$ lacking such a biological membrane coating. We have previously shown that this physical lipid structure may play a role in the programming of obesity risk later in life ${ }^{(21)}$. We developed a concept IMF in which the lipid droplets had physical properties similar to those of lipid droplets in human milk, i.e. larger in size and coated with PL (Nuturis ${ }^{\circledR}$; Danone Research), and investigated whether postnatal exposure to this Concept IMF protects against excessive fat accumulation in adulthood. Although adult body weight (BW) was comparable between the Control IMF- and Concept IMF-fed mice challenged by a mild Western-style diet (WSD) from adolescence, adult fat mass (FM) was $28 \%$ lower in the mice fed the Concept IMF in early life. This was accompanied by an improved metabolic profile since adult fasting plasma lipids as well as plasma glucose, resistin and leptin levels were lower in the Concept IMF group. Taken together, these data suggest that the sustained effects on adult FM were mediated through differences in WAT development. We hypothesised that the exposure of pre-weaning mice to the Concept IMF with large PL-coated lipid droplets alters WAT development by limiting hyperplastic and hypertrophic growth affecting the metabolic functions of WAT and ultimately leading to reduced adult body fat accumulation.

In the present study, we investigated the morphological WAT characteristics and gene expression of transcription factors that play a key role in adipocyte differentiation and lipogenesis to gain more insights into the mechanism underlying the programming effects of the Concept IMF on adult body composition.

\section{Methods}

\section{Animals and study design}

All experimental procedures were approved by the Animal Experimental Committee DEC-Consult, Bilthoven, The Netherlands, and complied with the principles of laboratory animal care. Mice were housed at Wageningen University and Research Centre (CKP, WUR, Wageningen, The Netherlands) under a $12 \mathrm{~h}$ light $-12 \mathrm{~h}$ dark cycle (lights on at 06.00 hours $=$ Zeitgeber time $0 \mathrm{~h})$ in a temperature- and humidity-controlled room $\left(21 \pm 2^{\circ} \mathrm{C}\right.$ and $50 \pm 5 \%$, respectively). Food and water were available ad libitum during the entire experimental protocol. BW was measured per litter before weaning and individually after weaning twice a week. Male and female C57BL/6J mice were time-mated. Dams were assigned to the American Institute of Nutrition-93G diet during pregnancy and lactation. After birth, pups were randomly cross-fostered, i.e. all pups from one litter were assigned to different dams, and litters were culled to four male and two female pups on postnatal day (PN)2. Litters were randomly assigned to one of the two experimental diets on PN16. After weaning on PN21, female pups were killed; male pups were housed in pairs and continued to be fed their respective diets until PN42, followed by a WSD. Food intake was measured weekly per cage between PN42 and 98.

To address the effects of the WSD challenge in adolescence and adulthood, we included a separate non-challenged reference group (Reference), which was maintained on the Control IMF until PN42 and then fed a standard semi-synthetic rodent chow until dissection on PN98 (Fig. 1). BW, FM and lean body mass were measured on PN42, 70 and 98 by dual-energy X-ray absorptiometry (PIXImus; GE Lunar) under general anaesthesia (isoflurane $/ \mathrm{N}_{2} \mathrm{O} / \mathrm{O}_{2}$ ). Relative $\mathrm{FM}$ was calculated as the percentage of $\mathrm{FM}(\% \mathrm{FM})$ of total $\mathrm{BW}$.

\section{Infant milk formula production and analyses}

As a basis for the Control IMF rodent diet, an IMF powder was prepared according to a standard stage 1 IMF recipe (for infants aged between 0 and 6 months) and a processing procedure (Danone Research). The Concept IMF powder that served as a basis for the Concept IMF rodent diet was prepared by adding $0.5 \mathrm{~g} / \mathrm{l} \mathrm{PL}$ of dairy origin (Fonterra Co-operative Group Limited; Table 1) and applying an altered processing procedure to obtain PLcoated lipid droplets larger than those in a standard IMF. Briefly, the polar PL were added to the aqueous phase and blended with the lipid phase containing the neutral vegetable lipids to generate a PL coating around the lipid droplets. Homogenisation 


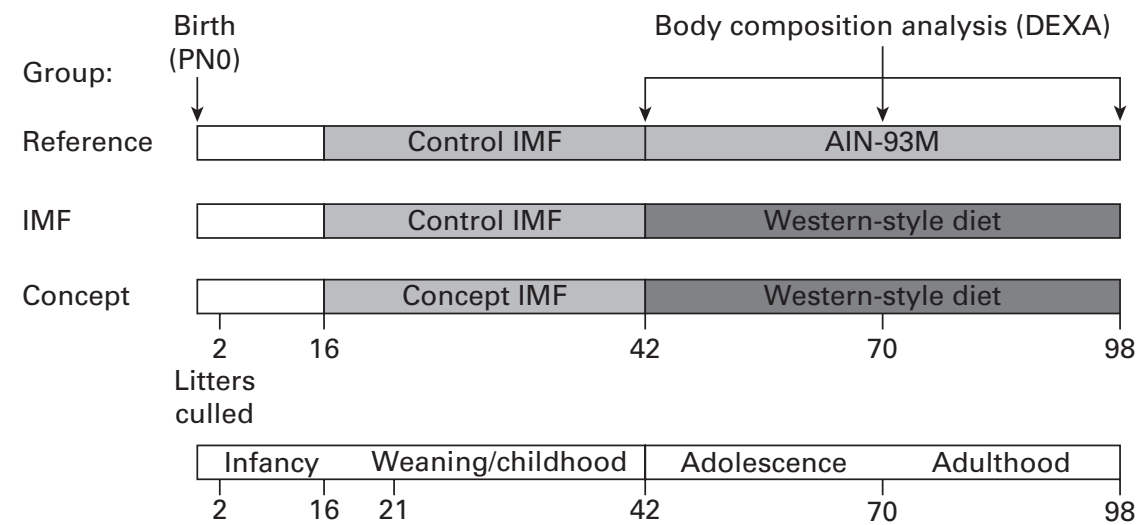

Fig. 1. Study design. DEXA, dual-energy X-ray absorptiometry; IMF, infant milk formula; PN, postnatal day.

pressure during processing was adjusted to obtain a homogeneous mixture of ingredients and also to retain a large lipid droplet size ${ }^{(22)}$. Initial differences in FA composition between diets as a result of the dairy origin of the PL source that were not corrected for in the previous study ${ }^{(22)}$ were compensated for by minor adjustments to the composition of the vegetable oil blend. Both IMF recipes contained $0.35 \mathrm{~g}$ arachidonic acid and $0 \cdot 2 \mathrm{~g} \mathrm{DHA} / 100 \mathrm{~g}$ total FA.

Lipid droplet size distribution of the IMF powders was measured using a Mastersizer laser light-scattering analyser with a refractive index ratio of 1.46 (Mastersizer 2000, Hydro 2000G, Malvern Instruments Limited). PL in the coated lipids were visualised using epifluorescence microscopy (Carl Zeiss Benelux). Solubilised IMF was incubated with Annexin-V Alexa Fluor $^{\circledR} 488$ (Invitrogen - Molecular Probes) and Nile Red (Sigma-Aldrich) according to the manufacturer's protocol for staining PL and TAG, respectively, and labelling of the fat core and PL coating in the non-fixed lipid droplets. Analyses were performed using a fluorescence microscope (Zeiss Axioplan 2; Carl Zeiss) with a $(10) \times 63$ oil immersion objective using fluorescein isothiocyanate (FITC) and tetramethylrhodamine isothiocyanate (TRITC) optical filters (Carl Zeiss Benelux).

\section{Experimental diets}

All experimental diets were semi-synthetic (Research Diet Services; Table 1) and had a macronutrient and micronutrient composition according to the American Institute of Nutrition formulation of American Institute of Nutrition-93G purified diets for laboratory rodents ${ }^{(23)}$. The postnatal IMF-based rodent diets contained $28.3 \mathrm{w} / \mathrm{w} \%$ Control or Concept IMF powder, respectively, and were complemented with protein and carbohydrates to meet rodent nutrient requirements. These diets were not pelletised, but given to the mice as dough (powder mixed with water) in order to preserve the lipid structure. The moderate WSD consisted of $10 \%(\mathrm{w} / \mathrm{w})$ fat $(5 \%(\mathrm{w} / \mathrm{w})$ lard and $0 \cdot 1 \%(\mathrm{w} / \mathrm{w})$ cholesterol).

\section{Blood sampling and dissection}

Blood was sampled by cheek puncture under anaesthesia (isoflurane $/ \mathrm{N}_{2} \mathrm{O} / \mathrm{O}_{2}$ ) on PN42 after $4 \mathrm{~h}$ of fasting during the light phase ${ }^{(24)}$. Plasma was pooled per three mice per group to obtain sufficient samples for analyses. At dissection (PN98), mice were terminally anaesthetised (isoflurane $/ \mathrm{N}_{2} \mathrm{O} / \mathrm{O}_{2}$ ) after $4 \mathrm{~h}$ of fasting. Dual-energy X-ray absorptiometry scans were

Table 1. Composition of the experimental diets

\begin{tabular}{|c|c|c|c|c|}
\hline & \multicolumn{4}{|c|}{ IMF } \\
\hline & Control & Concept & WSD & AIN-93M \\
\hline Carbohydrates (g/kg) & 645 & 645 & 600 & 720 \\
\hline Sugars (g/kg) & 235 & 235 & 150 & 100 \\
\hline Dextrose $(\mathrm{g} / \mathrm{kg})$ & 5 & 5 & 150 & - \\
\hline Lactose $(\mathrm{g} / \mathrm{kg})$ & 145 & 145 & - & - \\
\hline Sucrose $(\mathrm{g} / \mathrm{kg})$ & 85 & 85 & - & 100 \\
\hline Polysaccharides (g/kg) & 410 & 410 & 450 & 620 \\
\hline Maltodextrin $(\mathrm{g} / \mathrm{kg})$ & 50 & 50 & 250 & 155 \\
\hline Starch $(\mathrm{g} / \mathrm{kg})$ & 360 & 360 & 200 & 465 \\
\hline Protein $(\mathrm{g} / \mathrm{kg})$ & 179 & 179 & 179 & 126 \\
\hline Soya (g/kg) & 150 & 150 & 179 & 126 \\
\hline Whey $(\mathrm{g} / \mathrm{kg})$ & 17 & 17 & - & - \\
\hline Casein $(\mathrm{g} / \mathrm{kg})$ & 12 & 12 & - & - \\
\hline Fat $(\mathrm{g} / \mathrm{kg})$ & 70 & 70 & 100 & 40 \\
\hline Oil blend* (g/kg) & $69 \cdot 1$ & 64.4 & 50 & - \\
\hline Milk fat $(\mathrm{g} / \mathrm{kg})$ & 0.9 & $5 \cdot 6$ & - & - \\
\hline Lard $(\mathrm{g} / \mathrm{kg})$ & - & - & 50 & - \\
\hline Soya oil (g/kg) & - & - & - & 40 \\
\hline SFA (g/kg) & $28 \cdot 7$ & $29 \cdot 7$ & 41.9 & 5.9 \\
\hline MUFA (g/kg) & $26 \cdot 5$ & $26 \cdot 1$ & $42 \cdot 3$ & $10 \cdot 3$ \\
\hline PUFA (g/kg) & 11.5 & $11 \cdot 0$ & $13 \cdot 2$ & 23.5 \\
\hline LA $(18: 2 n-6)(\mathrm{g} / \mathrm{kg})$ & 9.8 & 9.3 & 11.9 & $20 \cdot 4$ \\
\hline ALA $(18: 3 n-3)(\mathrm{g} / \mathrm{kg})$ & 1.8 & 1.7 & 1.3 & $2 \cdot 7$ \\
\hline ARA $(20: 4 n-6)(\mathrm{g} / \mathrm{kg})$ & 0.25 & 0.25 & - & - \\
\hline EPA $(20: 5 n-3)(\mathrm{g} / \mathrm{kg})$ & 0.03 & 0.04 & - & - \\
\hline DHA $(22: 6 n-3)(\mathrm{g} / \mathrm{kg})$ & 0.14 & 0.14 & - & - \\
\hline LA:ALA & 5.4 & 5.3 & 9.5 & 7.5 \\
\hline Total $n-6: n-3$ & $5 \cdot 1$ & $5 \cdot 0$ & 9.5 & 7.5 \\
\hline Phospholipids† (g/kg) & 0.1 & 1.1 & - & - \\
\hline Cholesterol (mg/kg) & 4.7 & $20 \cdot 4$ & 1000 & - \\
\hline $\begin{array}{l}\text { Cellulose } \\
\quad \text { (Vitacel L 600-20) (g/kg) }\end{array}$ & 50 & 50 & 50 & 50 \\
\hline Mineral mix (g/kg) & 35 & 35 & 35 & 35 \\
\hline Vitamin mix (g/kg) & 10 & 10 & 10 & 10 \\
\hline Choline bitartrate $(\mathrm{g} / \mathrm{kg})$ & 2.5 & 2.5 & 2.5 & 2.5 \\
\hline L-Cysteine (g/kg) & 3 & 3 & 3 & 3 \\
\hline $\begin{array}{l}\text { tert-Butylhydroquinone } \\
(\mathrm{g} / \mathrm{kg})\end{array}$ & 0.014 & 0.014 & 0.014 & 0.014 \\
\hline
\end{tabular}

IMF, infant milk formula; WSD, Western-style diet; AIN, American Institute of Nutrition; LA, linoleic acid; ALA, $\alpha$-linolenic acid; ARA, arachidonic acid. ${ }^{*}$ Mixture of oils, among others rapeseed, sunflower, fish, coconut and palm oils. † Phospholipids derived from bovine milk. 
performed, and blood was collected in $\mathrm{K}_{3}$ EDTA-coated tubes via cardiac puncture. Liver, pancreas, $m$. tibialis, brain and WAT depots (epididymal (EPI), retroperitoneal, perirenal and inguinal (ING)) were collected and weighed. Plasma was obtained by centrifugation at $1350 \mathrm{~g}$ for $12 \mathrm{~min}$ at $4^{\circ} \mathrm{C}$ and stored at $-80^{\circ} \mathrm{C}$.

\section{Plasma analyses}

Total cholesterol (TC), HDL-cholesterol (HDL-C), LDLcholesterol (LDL-C), VLDL-cholesterol and TAG concentrations were determined colorimetrically after enzymatic conversion (Reinier de Graaf Laboratory).

Plasma glucose concentration (GOD-PAP method; Roche Diagnostics) was measured colorimetrically in PN98 plasma samples and analysed using a microplate imaging system (Bio-Rad Laboratories, Inc.). Plasma insulin concentration was measured by means of ELISA (DRG) according to the manufacturer's protocol. Homeostasis model assessment of insulin resistance was calculated from fasting plasma glucose and insulin concentrations (glucose $(\mathrm{mmol} / \mathrm{l}) \times$ insulin $(\mathrm{pmol} / \mathrm{l}) / 22 \cdot 5)$ as an indirect measure of insulin sensitivity. Plasma volumes were insufficient to perform glucose and insulin analyses on PN42 samples.

\section{Cytological and biochemical analyses of adipose tissue}

Cell size distribution according to the optical method of Di Girolamo \& Fine ${ }^{(25)}$ was determined in fresh ING and EPI WAT depots, respectively, representing subcutaneous and abdominal fat. Depots were cut into large pieces of $1 \mathrm{~mm}$ and incubated in gassed $\left(95 \% \mathrm{O}_{2} / 5 \% \mathrm{CO}_{2}\right)$ Krebs-Ringer bicarbonate buffer ( $\mathrm{pH} 7 \cdot 4,2 \mathrm{mg}$ collagenase type II/ml; Gibco for Invitrogen) at $37^{\circ} \mathrm{C}$. The digested tissue was filtered first through a $250 \mu \mathrm{m}$ cell strainer, washed three times with Krebs-Ringer bicarbonate buffer and filtered again through a $40 \mu \mathrm{m}$ cell strainer.

Images of isolated adipocytes were captured using an Axioplan 2 Zeiss microscope (Carl Zeiss) and a Sony DXC-950P video camera (Sony). For the assessment of mean adipocyte volume and size distribution per mouse, six representative sections per slide and six slides per depot per mouse were used to obtain images of at least 300 cells using analysis software (Soft Imaging System).

The remaining WAT depots were snap-frozen and stored at $-80^{\circ} \mathrm{C}$ for lipid content measurement. Lipid extraction was performed according to the method of Folch et al. ${ }^{(26)}$ using dichloromethane-methanol $(2: 1, \mathrm{v} / \mathrm{v})$.

WAT cellularity was calculated by dividing the fat pad lipid content by mean adipocyte weight. The mean adipocyte weight was calculated by multiplying the mean adipocyte volume by lipid density, which was derived from a triolein density $(\rho)$ of $0.915 \mathrm{~g} / \mathrm{ml}^{(25)}$.

\section{Gene expression analyses in epididymal white adipose tissue depot}

Total RNA was isolated from epididymal WAT using the RNeasy Mini Kit (Qiagen). Complementary DNA (cDNA) was prepared using the iScript cDNA Synthesis Kit (Bio-Rad), and quantitative real-time PCR analysis was performed using the CFX96 RealTime PCR Detection System (Bio-Rad) with iQ SYBR Green Supermix (Bio-Rad). Validated quantitative PCR primers (Table 2) were obtained for leptin from SABiosciences (Qiagen) and for $P P A R \gamma, C E B P \alpha, C E B P \beta, C E B P \delta, R X R \alpha$, sterol regulatory element-binding protein 1c (SREBP1C) and ribosal protein S13 (RPS13) from Isogen Life Science. mRNA expression was calculated using the CFX Manager software (version 1.6; Biorad) and corrected for the expression of the housekeeping gene RPS13 ${ }^{(27)}$.

\section{Statistical analyses}

Statistical analyses were performed using SPSS 15.0.1 software (SPSS Benelux). Variables were checked for Gaussian distribution with the Shapiro-Wilk test. Levene's test for equality of variance was used to estimate the probability that the treatment groups had different variances. Direct and programming effects of any experimental diet (Control IMF, Concept IMF or Reference) on the development of body composition were analysed using a repeated-measures ANOVA. Post hoc analyses were performed on significant diet $\times$ time interactions using univariate ANOVA on PN42, 70 and 98 separately. Repeated-measures ANOVA was performed to analyse diet effects on the frequency distribution of adipocyte size on PN98 and a post hoc analysis was performed when significant diet $\times$ time interactions were confirmed. The effects of experimental diets on WAT weight, organ weight, plasma parameters, average adipocyte number and gene expression on PN98 were analysed by means of a univariate ANOVA.

Data are presented as means with their standard errors, unless otherwise indicated. Differences were considered significant at $P<0 \cdot 05$.

\section{Results}

\section{Infant milk formula-based diets}

The adjusted IMF processing and addition of $0.5 \mathrm{~g} / 1 \mathrm{PL}$ from dairy origin resulted in a Concept IMF powder with PL-coated (Fig. 2) lipid droplets larger than those in the Control IMF (Table 3).

\section{Direct effect of the Control and Concept IMF}

BW gain in the Control IMF- and Concept IMF-fed mice was similar from PN2 to $42(F(2,31)=0.758, P=0.477$; data not shown). Additionally, there was no direct effect of the diet during early development on body composition, since BW, lean body mass, FM and \%FM were comparable (Fig. 3) on PN42. Plasma TAG, TC, HDL-C, LDL-C and VLDL-cholesterol concentrations were similar in all the groups (Table 5).

\section{Programming effect of the Concept IMF during adult Western-style diet challenge}

Body composition and food intake. BW gain during the WSD challenge was significantly lower in the Concept 
Table 2. Quantitative PCR primers

\begin{tabular}{|c|c|c|c|}
\hline Amplified region & Forward primer & Reverse primer & Annealing temperature $\left({ }^{\circ} \mathrm{C}\right)$ \\
\hline$P P A R \gamma$ & 5'-AGATTAATAGTTTGACGGGGTTT-3' & 5'-ACCCGTATCCССТCTAATCGA-3' & 62 \\
\hline CEBPS & 5'-AGAGCGCCATCGACTTCAGC-3' & 5'-CCAAGCTCACCACTGTCTGC-3' & 63 \\
\hline$C E B P \beta$ & $5^{\prime}$-TACCCAGGACCCATTGGATA-3' & 5'-TTCACTTGGCCACTCTTCCT-3' & 62 \\
\hline$C E B P \alpha$ & 5'-TGTTGGAGTTGACCAGTGAC-3' & 5'-ATCCAGCGACCCTAAACCAT-3' & 60 \\
\hline$R X R \alpha$ & 5'-GATGGCCTGTGTGGATCTTT- $3^{\prime}$ & $5^{\prime}$-AACCAGCAACCAGAACAAGC-3' & 60 \\
\hline SREBP1C & 5'-CAAGTGCTGCAGGAAACTGA-3' & 5'-CATGGCCTTGTCAATGGAAC-3' & 60 \\
\hline Leptin & SABiosciences $^{\circledR}$ & & 63 \\
\hline
\end{tabular}

$C E B P, C C A A T /$ enhancer-binding protein; $R X R$, retinoid $\mathrm{X}$ receptor; SREBP1C, sterol regulatory element-binding protein $1 \mathrm{c}$.

IMF mice compared with the Control IMF mice $(P=0 \cdot 028$; Fig. 3). The BW difference was exclusively due to a lower FM gain in the Concept IMF mice compared with the Control IMF mice, since lean body mass gain from PN42 to 98 was similar in both the groups. Early postnatal Concept IMF exposure reduced FM gain due to the WSD challenge by $30 \%$ and $\% \mathrm{FM}$ gain by $20 \%$ compared with Control IMF exposure. The \%FM in the Concept IMF mice was similar to that in the non-challenged Reference mice ( $P=0.234)$ on $\mathrm{PN} 70$ and showed intermediate values on PN98 ( $P=0.001$ and $P=0.012$ ) for the Control and nonchallenged Reference mice, respectively (Fig. 4). The weights of WAT depots followed a similar pattern as total FM and \%FM, with 26-34\% lower WAT depot weights being observed in the Concept IMF mice compared with the Control IMF mice. Average liver weight of the Concept IMF mice was significantly lower than liver weight of the Control IMF mice and comparable to that of the Reference mice $(F(2,31)=5 \cdot 656, P=0 \cdot 008$; Table 4). Food intake was similar in both the groups (53.09 (SEM 1.3) v. 50.88 (SEM $0 \cdot 8) \mathrm{kJ} / \mathrm{d}$ per mouse for the Control and Concept IMF groups, respectively).

Adipocyte size and number. We aimed to address whether the differences in FM were related to a decrease in adipocyte number, adipocyte size or both in fat depots representing subcutaneous and abdominal fat ${ }^{(9,10)}$. The data on cell number
(Fig. 4) showed that this parameter was not affected by early dietary exposure; there was no difference in adipocyte number in the EPI and ING WAT depots of the Control IMF and Concept IMF groups.

The early diet did affect adipocyte size. Cell size distribution curves illustrate that mice fed the Concept IMF before the WSD challenge had a significantly smaller number of large adipocytes in the ING depot compared with the Control IMF mice $(F(14,266)=3 \cdot 199, P=0 \cdot 002)$. This difference was mainly found in the cell size category between 80 and $150 \mu \mathrm{m}$ diameter. Average ING adipocyte volume was $25 \%$ lower in the Concept IMF group compared with the Control IMF group $(t(18)=2 \cdot 016, P<0 \cdot 05)$. Average EPI adipocyte volume at the end of the WSD challenge was $21 \%$ lower in the Concept IMF mice compared with the Control IMF mice, but this difference did not reach significance. As stated earlier, hyperplastic and hypertrophic growth of WAT is regulated by transcription factors, including $\operatorname{PPAR} \gamma, \operatorname{RXR} \alpha, \operatorname{CEBP}$ and SREBP1c. The expression of PPAR $\gamma \quad(F(1,7)=4 \cdot 701$, $P<0.01), \operatorname{RXR} \alpha(F(1,7)=1.919, P<0.05)$ and $C E B P \alpha(F(1,3)$ $=15.90, P<0.001)$ was decreased in the EPI WAT depots of the Concept IMF compared with the Control IMF mice. No differences in the expression of $C E B P \beta, C E B P \delta$ or SREBP1C were observed between both the IMF groups. The expression of leptin was significantly lower $(F(1,7)=2 \cdot 077, P<0 \cdot 05)$
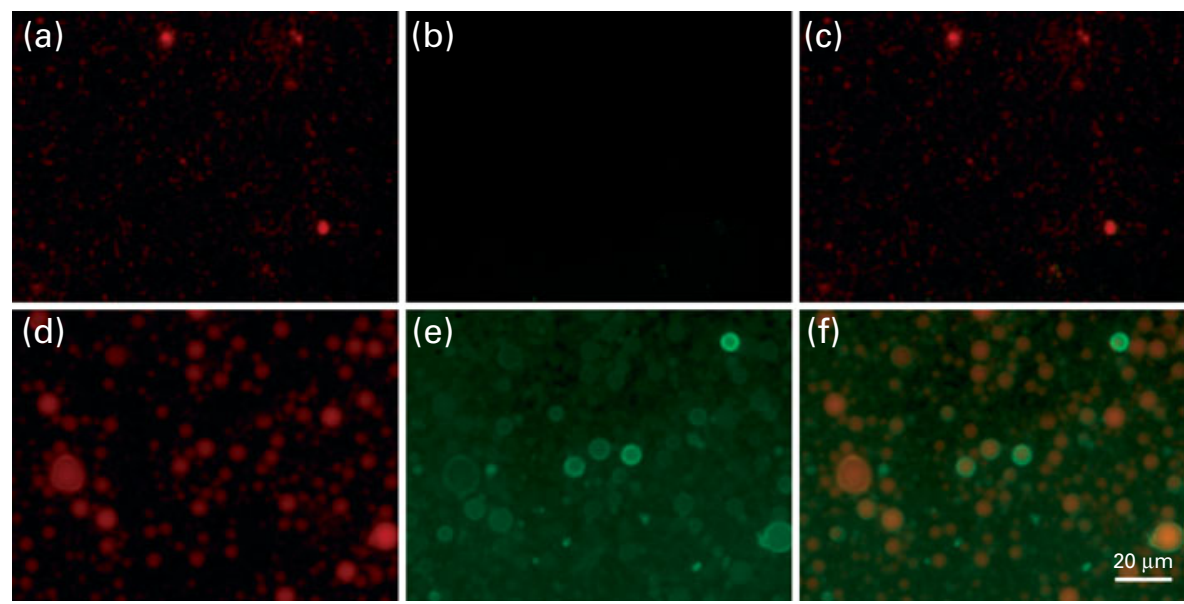

Fig. 2. Images of conventional epifluorescence microscopy with Nile Red-stained fat core (a, d), Annexin-V Alexa Fluor ${ }^{\circledR}$ 488-stained PL (b, e) and composed image of both $(c, f)$ the Control and Concept IMF, respectively. 
Table 3. Lipid droplet size characteristics of the Control infant milk formula (IMF) and Concept IMF derived from the particle size distribution analysis

\begin{tabular}{lcc}
\hline & Control IMF & Concept IMF \\
\hline$D(0.1)^{\star}(\mu \mathrm{m})$ & 0.183 & 0.407 \\
$D(0.5)^{*}(\mu \mathrm{m})$ & 0.349 & 4.951 \\
$D(0.9)^{*}(\mu \mathrm{m})$ & 0.855 & 11.67 \\
$D(1.0)^{*}(\mu \mathrm{m})$ & 1.633 & 23.24 \\
$D[3,2] \dagger(\mu \mathrm{m})$ & 0.285 & 1.337 \\
$D[4,3] \ddagger(\mu \mathrm{m})$ & 0.468 & 6.000 \\
$<1 \mu \mathrm{m} \S(\%)$ & 94.34 & 12.59 \\
$2-12 \mu \mathrm{m} \|(\%)$ & 0.000 & 70.30 \\
Mode $(\mu \mathrm{m})$ & 0.439 & 6.500 \\
\hline
\end{tabular}

* $10,50,90$ and $100 \%$ particle volume percentiles.

† Surface-weighted average diameter.

$\ddagger$ Volume-weighted average diameter.

$\S$ Sum volume of particles $<1.000 \mu \mathrm{m}$ ( $\%$ total volume of all particles).

I Sum volume of particles of $2-12 \mu \mathrm{m}$ (\% total volume of all particles).

I Peak diameter of particle size distribution.

in the Concept IMF mice compared with the Control IMF mice (Fig. 5).

Plasma metabolic profile. Although both the IMF groups had higher concentrations of TC, HDL-C and LDL-C compared with the non-challenged Reference group $(P<0.05)$, the Concept IMF mice had markedly lower concentrations compared with the Control IMF mice $(P<0 \cdot 05)$. Experimental diets did not significantly affect any of the analysed parameters for glucose homeostasis (Table 5).
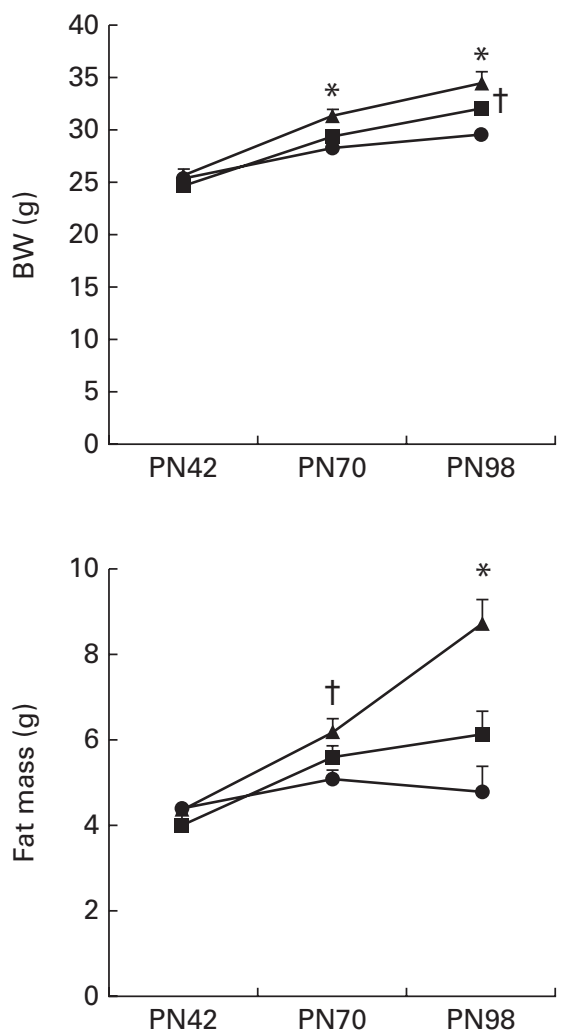

Effect of the Western-style diet challenge during adolescence and adulthood

To confirm that the mild WSD indeed represented a diet challenge that affects adult phenotype, we compared the Control IMF group fed the WSD in adulthood with a non-challenged Reference group that was switched to a standard rodent chow on PN42.

WSD intake enhanced BW gain (17\%) in the Control IMF mice compared with the non-challenged Reference mice (Fig. 3; $P=0.002$ ) from PN42 to 98. Lean body mass gain was similar in both the groups $(F(2,31)=0.056, P=0.956)$, but the WSD challenge increased FM by $80 \%$ and \%FM by $50 \%$. The weights of $m$. tibialis, pancreas and brain were unaffected (Table 4), whereas average liver weight of the Control IMF mice was higher compared with the Reference mice $(F(2,31)=5 \cdot 656, P=0 \cdot 008)$.

The WSD challenge resulted in more large adipocytes in the Control IMF group compared with the Reference group. Average EPI adipocyte volume was $94 \%$ increased as a result of the $56 \mathrm{~d}$ WSD challenge, whereas average ING adipocyte volume appeared to be only $17 \%$ higher following the WSD challenge. This difference did not reach significance (data not shown). The Control IMF and Reference groups had comparable adipocyte numbers in both the EPI and ING depots (data not shown).
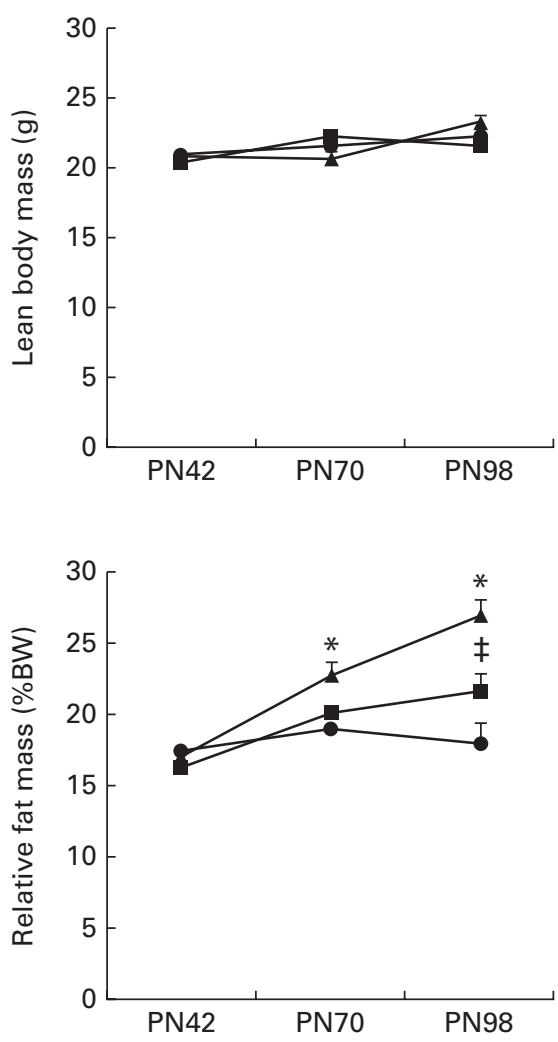

Fig. 3. Development of body composition ((a) body weight (BW), (b) lean body mass, (c) fat mass and (d) relative fat mass (\%BW)) during the Western-style diet challenge of mice fed the early Control IMF $(\boldsymbol{\Delta} ; n$ 11) or Concept IMF $(\boldsymbol{\square} ; n 11)$ and the Reference group ( $n$; $n$ 12) fed the American Institute of Nutrition-93M diet from postnatal day (PN)42 to 98 . Values are means, with their standard errors represented by vertical bars. * Mean value was significantly different from that of the Reference and Concept IMF groups $(P<0.05)$. † Mean value was significantly different from that of the Reference group $(P<0.05)$. $¥$ Mean value was significantly different from that of the Reference and Control IMF groups $(P<0.05)$. 


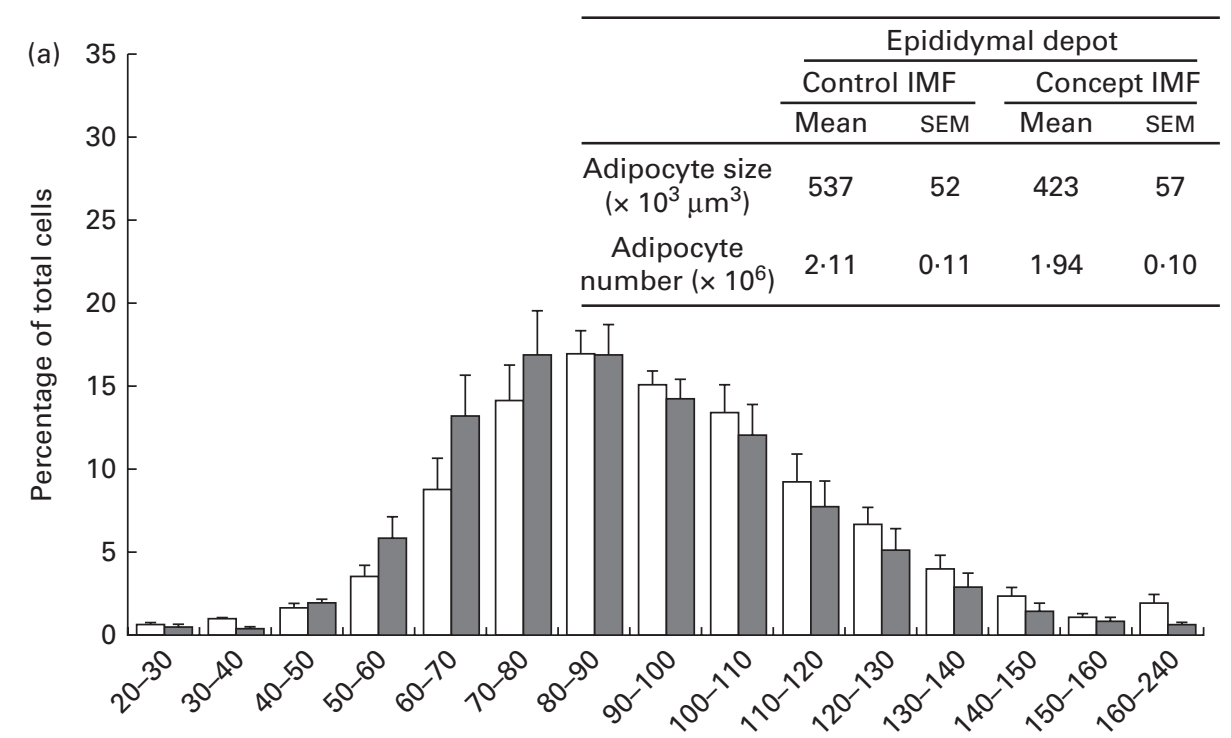

Cell size distribution (diameter, $\mu \mathrm{m}$ )

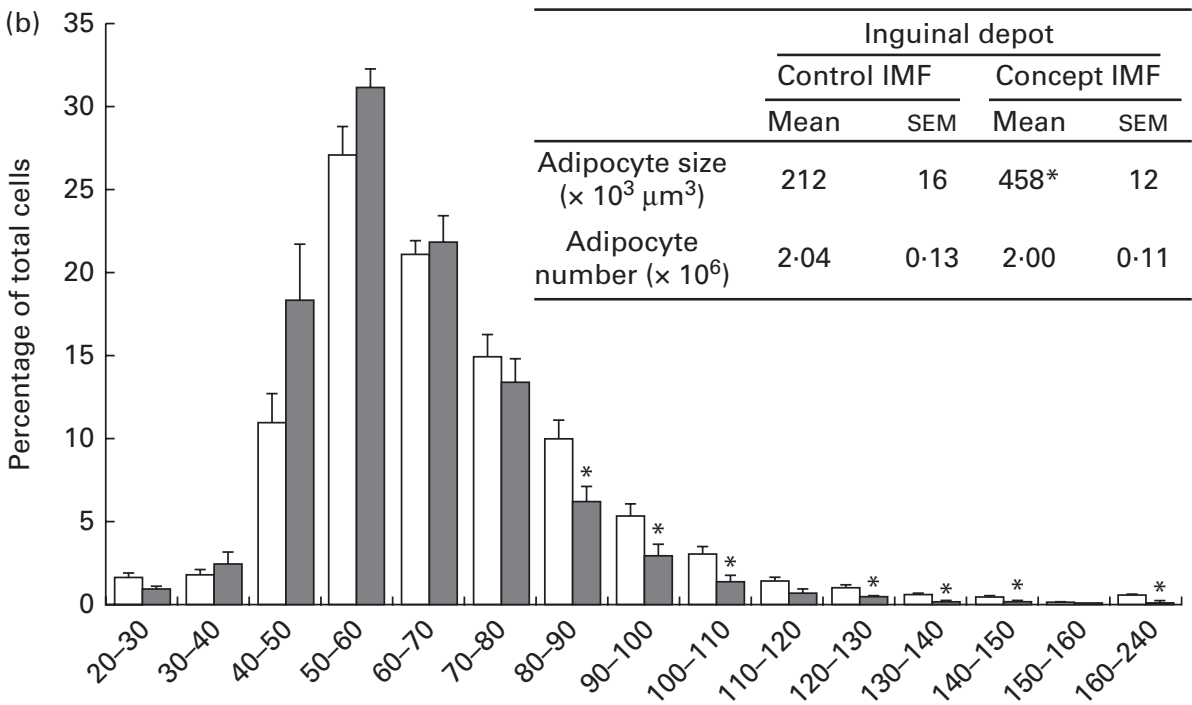

Cell size distribution (diameter, $\mu \mathrm{m}$ )

Fig. 4. Frequency distribution of adipocyte size, average cell size and number of epididymal (a) and inguinal (b) white adipose tissue depots on postnatal day (PN)98 in the Control infant milk formula (IMF) ( $\square$ ) and Concept IMF ( $\square$ ) groups. Values are means ( $n$ 9-12 mice per group), with their standard errors represented by vertical bars. ${ }^{*}$ Mean value was significantly different from that of the Control IMF group $(P<0.05)$.

Fasting plasma TC $(F(2,27)=17 \cdot 352, \quad P<0 \cdot 001)$, HDL-C $(F(2,27)=19 \cdot 686, \quad P=0.049)$ and LDL-C $(F(2,27)=18.424$, $P<0.001)$ concentrations were increased in the WSD-challenged Control IMF mice compared with the non-challenged Reference group. Fasting plasma TAG, glucose, insulin and homeostasis model assessment of insulin resistance concentrations were not affected on PN98 due to the WSD challenge; the concentrations of the Control IMF and Reference mice were not significantly different (Table 5).

\section{Discussion}

The present study demonstrated that the physical structure of dietary lipids programmes body composition development of pre-weaning mice towards reduced body fat accumulation in adulthood. These findings are in line with our previous study $^{(22)}$, despite differences in FA composition, indicating that the physical lipid structure indeed is the main determinant of the programming effect. The programming of adult FM by the Concept IMF was not mediated by a reduction in the number of adipocytes, but rather by a reduction of adipocyte size, indicating reduced lipid storage. The phenotype coincided with a reduced expression of transcription factors that promote lipogenesis in WAT.

\section{Reduced adult fat mass and lipogenic gene expression}

The development of human WAT starts in the third trimester of gestation and continues in postnatal life through the 
Table 4. Average weight of white adipose tissue (WAT) depots and organs on postnatal day (PN)98 during the Western-style diet challenge of mice fed the Control infant milk formula (IMF) or Concept IMF and the Reference group fed the American Institute of Nutrition-93M diet from PN42 to 98

(Mean values with their standard errors, $n 11-12$ )

\begin{tabular}{|c|c|c|c|c|c|c|}
\hline & \multicolumn{2}{|c|}{ Reference } & \multicolumn{2}{|c|}{ Control IMF } & \multicolumn{2}{|c|}{ Concept IMF } \\
\hline & Mean & SEM & Mean & SEM & Mean & SEM \\
\hline \multicolumn{7}{|l|}{ WAT } \\
\hline Epididymal (mg) & $516 \cdot 8$ & 39.9 & $1138 \cdot 0^{*}$ & 99.7 & $827 \cdot 2^{*} \dagger$ & $106 \cdot 5$ \\
\hline Perirenal (mg) & $26 \cdot 2$ & $2 \cdot 7$ & $67.4^{*}$ & $8 \cdot 3$ & $43 \cdot 8^{*} \dagger$ & 5.5 \\
\hline Retroperitoneal (mg) & 137.5 & $10 \cdot 4$ & $299 \cdot 8^{*}$ & $26 \cdot 3$ & $215 \cdot 2^{*} \dagger$ & 29.5 \\
\hline Inguinal (mg) & $374 \cdot 8$ & $32 \cdot 0$ & $542 \cdot 8^{*}$ & $40 \cdot 3$ & $401 \cdot 7 \dagger$ & 28.4 \\
\hline Liver (g) & 1.41 & 0.0 & $1 \cdot 69^{*}$ & 0.1 & 1.57 & $0 \cdot 1$ \\
\hline Pancreas (mg) & $159 \cdot 3$ & 8.0 & 167.5 & 7.8 & $172 \cdot 1$ & 9.5 \\
\hline M. tibialis (mg) & $50 \cdot 4$ & $2 \cdot 3$ & $49 \cdot 2$ & 0.8 & $50 \cdot 9$ & 0.8 \\
\hline Brain $(\mathrm{mg})$ & 425.8 & $7 \cdot 6$ & $413 \cdot 0$ & $7 \cdot 1$ & $422 \cdot 2$ & $6 \cdot 0$ \\
\hline
\end{tabular}

* Mean value was significantly different from that of the Reference group $(P<0.05)$.

† Mean value was significantly different from that of the Control IMF group $(P<0.05)$.

proliferation of preadipocytes and subsequent differentiation, resulting in mature adipocytes storing energy in the form of lipids ${ }^{(1)}$. The amount of total body FM is determined by adipocyte size and by the number of differentiated adipocytes in WAT $^{(2,28)}$. Feeding the Concept IMF for a relatively short period in early life partially prevented excess body fat accumulation upon a WSD challenge in later life. The Concept IMF mice exhibited a reduced storage of TAG compared with the Control IMF mice. The reduced gene expression of leptin in the Concept IMF mice compared with the Control IMF mice reflects both reduced FM and reduced adipocyte size ${ }^{(29)}$. The reduced lipid accumulation upon the WSD challenge in the WAT of adult mice in the Concept IMF group was associated with reduced expression of PPAR $\gamma$ and $R X R \alpha$ mRNA in WAT, suggesting reduced FA uptake and/or de novo lipogenesis.
The expression of another key regulator of (de novo) FA and TAG synthesis, SREBP1c, was not affected by the postnatal diet. Possibly, the Concept IMF did not have a sustained impact on the expression of SREBP1c in WAT. Alternatively, the expression of SREBP1c is up-regulated by insulin, resulting in increased FA synthesis and reduced FA oxidation after feeding ${ }^{(30)}$. In the present study, the expression of SREBP1c was measured after $4 \mathrm{~h}$ of fasting, which may have blunted possible differences between the groups in fed state ${ }^{(31)}$. Additionally, as SREBP1c is expressed in both WAT and liver, the Concept IMF may have exerted organ- ${ }^{(32)}$ and WAT depot-specific $^{(33)}$ effects. Indeed, it is suggested that SREBP1c in WAT regulates the expression of genes involved in cholesterol metabolism rather than that of genes involved in FA and TAG synthesis ${ }^{(34)}$. (a)

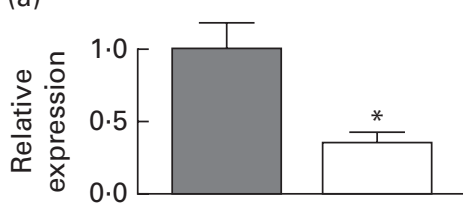

(d)

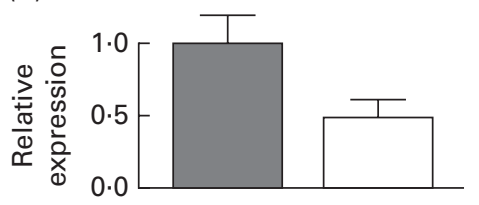

(g)

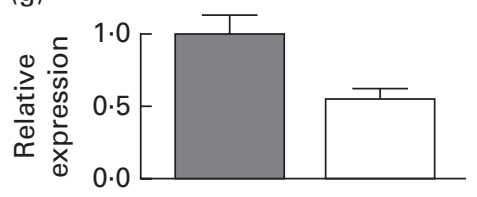

(b)
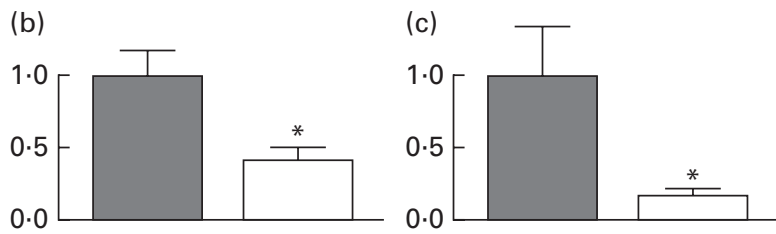

(e)
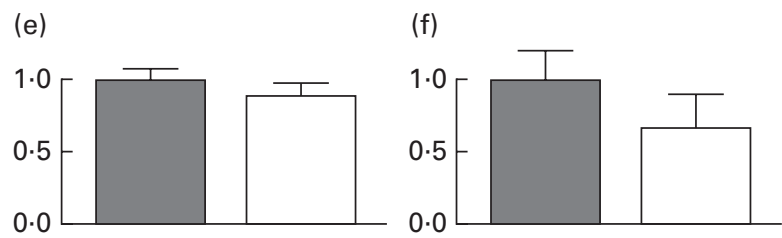
Table 5. Average fasting plasma parameters on postnatal day (PN)98 during the Western-style diet challenge of mice fed the Control infant milk formula (IMF) or Concept IMF and the Reference group fed the American Institute of Nutrition-93M diet from PN42 to 98

(Mean values with their standard errors, $n 2-4$ mice per group on PN42 and $n$ 8-11 mice per group on PN98)

\begin{tabular}{|c|c|c|c|c|c|c|}
\hline & \multicolumn{2}{|c|}{ Reference } & \multicolumn{2}{|c|}{ Control IMF } & \multicolumn{2}{|c|}{ Concept IMF } \\
\hline & Mean & SEM & Mean & SEM & Mean & SEM \\
\hline \multicolumn{7}{|l|}{ PN42 } \\
\hline TAG (mmol/l) & 1.66 & 0.1 & 1.44 & 0.1 & 1.85 & 0.1 \\
\hline $\mathrm{TC}(\mathrm{mmol} / \mathrm{l})$ & 3.48 & 0.1 & 3.58 & 0.2 & $3 \cdot 18$ & 0.1 \\
\hline $\mathrm{HDL}-\mathrm{C}(\mathrm{mmol} / \mathrm{l})$ & 1.84 & 0.0 & 1.88 & 0.2 & 1.63 & 0.1 \\
\hline LDL-C (mmol/l) & 0.89 & 0.1 & 1.04 & 0.1 & 0.71 & 0.1 \\
\hline VLDL-C (mmol/l/) & 0.76 & 0.1 & 0.66 & 0.0 & 0.84 & 0.1 \\
\hline \multicolumn{7}{|l|}{ PN98 } \\
\hline TAG $(\mathrm{mmol} / \mathrm{l})$ & 0.97 & 0.1 & 1.00 & 0.1 & 0.82 & 0.0 \\
\hline $\mathrm{TC}(\mathrm{mmol} / \mathrm{l})$ & 2.98 & 0.2 & $4.40 \dagger$ & 0.2 & $3 \cdot 79^{\star} \dagger$ & 0.1 \\
\hline $\mathrm{HDL}-\mathrm{C}(\mathrm{mmol} / \mathrm{l})$ & 1.76 & 0.1 & $2.63+$ & 0.1 & $2 \cdot 32^{*} \dagger$ & 0.1 \\
\hline LDL-C (mmol/l') & 0.77 & 0.1 & $1.31 \dagger$ & 0.1 & $1.09^{*} \dagger$ & 0.1 \\
\hline VLDL-C (mmol//l) & 0.44 & 0.1 & 0.45 & 0.0 & 0.37 & 0.0 \\
\hline Glucose $(\mathrm{mmol} / \mathrm{l})$ & 13.7 & $1 \cdot 1$ & $12 \cdot 0$ & 1.0 & $13 \cdot 2$ & 0.7 \\
\hline Insulin (pmol/l) & $90 \cdot 6$ & $24 \cdot 8$ & $109 \cdot 4$ & 29.9 & $70 \cdot 1$ & $7 \cdot 4$ \\
\hline HOMA-IR $((\mathrm{mmol} / \mathrm{l} \times \mathrm{pmol} / \mathrm{l}) / 22.5)$ & $42 \cdot 0$ & $12 \cdot 6$ & $56 \cdot 8$ & $14 \cdot 3$ & $42 \cdot 0$ & $5 \cdot 8$ \\
\hline
\end{tabular}

TC, total cholesterol; HDL-C, HDL-cholesterol; LDL-C, LDL-cholesterol; VLDL-C, VLDL-cholesterol; HOMA-IR, homeostasis model assessment of insulin resistance.

${ }^{*}$ Mean value was significantly different from that of the Control IMF group $(P<0.05)$.

† Mean value was significantly different from that of the Reference group $(P<0.05)$.

\section{Reduced adult fat mass reduced adipocyte size, but not adipocyte number}

The Concept IMF mice had approximately $30 \%$ less total FM after the WSD challenge compared with the Control IMF mice, which was reflected in all the four WAT depots measured. However, the programming of adipocyte size by the Concept IMF appeared to be more pronounced in subcutaneous ING depots than in abdominal EPI depots, despite the comparable depot weight reduction. This difference could be explained by the major difference in EPI size distribution in the size category with the largest cells $(150-240 \mu \mathrm{m})$. These cells represent a small proportion of the total cell population, but store a relatively large amount of lipids compared with the smaller adipocytes. Thus, large adipocytes contribute significantly to the average adipocyte volume and storage capacity. It is known that there are WAT depot-specific differences in the responsiveness of adipocytes to nutrients, growth patterns, and metabolic and endocrine activities ${ }^{(35-39)}$. For instance, WAT expansion in ageing rats was associated with hypertrophic growth in visceral depots and hyperplastic growth in subcutaneous depots ${ }^{(35)}$. Additionally, adipocyte size, number and gene expression have been shown to differ considerably between WAT depots in adult rodents ${ }^{(40,41)}$, which is in accordance with findings from human studies ${ }^{(42-44)}$. Several cohort studies have shown that fetal and postnatal growth velocity differentially affects human body fat distribution, with specifically rapid postnatal weight gain being strongly associated with visceral adiposity ${ }^{(45-48)}$. This suggests that the critical window for WAT development may be different for visceral and subcutaneous depots. Indeed, data from a Dutch infant cohort demonstrated that the amount of visceral body fat increased between 12 and 24 months of age, in contrast to the amount of subcutaneous fat, which remained constant over this period $^{(49)}$. These age-dependent growth differences might also appear in rodents, as DiGirolamo et al. ${ }^{(10)}$ demonstrated distinct adipose tissue growth patterns among fat depots at different stages of life in rats. Additionally, both early-life overnutrition $^{(50)}$ and undernutrition ${ }^{(51)}$ can modulate these differential depot growth patterns. Unfortunately, we were unable to investigate adipocyte size distribution and number in visceral depots other than EPI WAT due to the small fat depot size, providing insufficient material for analysis. Therefore, the present study could not provide conclusive evidence for postnatal nutritional programming of adipocyte number by the Concept IMF. One could hypothesise that the nutritional intervention was implemented after a critical window for adipogenesis. Earlier dietary exposure to exclude this possibility would require an artificially fed animal model. However, early-life handling is known to induce stress as a confounding factor since it influences later-life body composition and fat distribution ${ }^{(52,53)}$. Alternatively, the absence of a sustained effect on adipocyte number could be related to the fact that both IMF-containing early diets meet the requirements for normal growth and development. Therefore, there would be no need for the mice to utilise the plasticity of WAT to increase adipocyte number in response to this nutritional stimulus. It has been hypothesised by Spalding et al. ${ }^{(3)}$ that increased adipocyte number in early life is a major risk factor for adult obesity. However, it is still unclear whether this is a causal relationship; it is unknown whether increased adipocyte number itself predisposes to adult obesity or whether both increased adipocyte number and adult obesity are caused by, for instance, excessive energy intake during childhood through a different mechanism altogether. In accordance with this hypothesis, early postnatal overnutrition in rats has been found to 
specifically increase adipocyte number and thereby increase adult FM, but it did not affect adipocyte size ${ }^{(54)}$. Additionally, hyperplasia and cell turnover capacity are positively correlated with insulin sensitivity independent of BW, whereas hypertrophy is negatively correlated with insulin sensitivity ${ }^{(55)}$. Our data clearly indicate that early diets can induce programming activity that is independent of hyperplastic growth, but seems to affect the capacity of adipocytes to enlarge upon a WSD challenge.

As stated previously, critical periods for the hyperplastic growth of WAT encompass early postnatal life and adolescence $^{(2,56)}$; cell number remains constant in healthy non-obese adults ${ }^{(3)}$. However, in case of sustained excessive energy intake in obesity, adult WAT is still capable of adjusting by both hypertrophic and hyperplastic growth ${ }^{(57)}$. In the present study, the moderate WSD significantly increased adipocyte size compared with a standard chow, but was not such a severe challenge as to promote hyperplasia in adolescence and adulthood. We cannot exclude that hyperplasia would have occurred if a more severe dietary challenge was used. Thus, presently we cannot rule out the potential programming effects of the postnatal diet on hyperplastic WAT growth.

\section{Programming of adult fat mass and metabolic homeostasis}

We determined to what extent the observed differences in adult body composition and FM corresponded with other parameters of lipid homeostasis, such as plasma lipids. Plasma TC, HDL-C and LDL-C concentrations were reduced in the Concept IMF mice compared with the Control IMF mice. Liver weight of the Control IMF mice was greater than that of the non-challenged Reference mice, whereas liver weight of the Concept IMF mice did not differ significantly from that of both the groups. This may suggest an improved metabolic profile and perhaps the absence of ectopic lipid accumulation due to the Concept IMF. Since plasma TAG, glucose and insulin concentrations were not significantly perturbed by the moderate WSD challenge compared with a normal rodent chow, the limited improvement in adult glucose homeostasis and TAG concentrations of the Concept IMF-fed mice was to be expected.

\section{Effect of milk lipid physical structure: potential mechanisms}

Previous studies comparing the digestion of raw cows' milk with that of processed milk with different milk lipid droplet sizes and surface compositions have reported differences in gastric emptying, lipid digestion and $\beta$-oxidation rate ${ }^{(58-60)}$. The results suggest differences in the utilisation of these lipids for either $\beta$-oxidation or lipogenesis. In turn, this could underlie the early programming of lipid metabolism resulting in differences in the metabolic capacity of adipocytes.

The sustained effects of the Concept IMF on body composition and metabolic profile cannot simply be explained by reduced food intake. Although individual food intake during exposure to early diets could not be measured since it was provided as dough to the entire litters until weaning, BW and body composition were similar between the groups on PN42. Moreover, daily food intake was comparable between the groups during the WSD challenge. Possibly, the Concept IMF-fed mice utilise energy from the WSD differently by storing less energy as lipids in adipose tissue, suggesting a higher BMR. However, this information is currently not available. Future studies that may help us gain more insights into energy expenditure are pivotal. Also, further studies addressing which specific aspects of the Concept IMF, i.e. fat droplet size, PL addition and/or coating, may contribute to the observed long-term effects are ongoing.

\section{Conclusion}

In conclusion, early exposure to the Concept IMF resulted in a diet-resistant phenotype in adult life. The Concept IMF prevents excessive hypertrophic growth of WAT in adulthood despite unaltered adipogenesis. Our data support the hypothesis that early Concept IMF exposure programmes metabolic responses through altered gene expression of factors regulating adipose tissue lipogenesis. The present results provide support for the emerging notion that dietary lipid structure should be considered a key component of dietary lipid quality in early life and is a determinant in later-life obesity risk.

\section{Acknowledgements}

The present study was not supported by external funding. The study was funded by Danone Research which is the employer of the authors A. O., D. K, L. S., M. A.-B., S. R. and E. M. v. d. B. Owing to the participation of these employees in the study, Danone Research contributed to the study design, the conduct of the study, the analysis of the samples and data, the interpretation of the findings and the preparation of the manuscript.

A. O., D. K., L. S., M. A.-B., S. R. and E. M. v. d. B. are employed by Danone Research. H. J. V. is a consultant for Danone Research outside the submitted work, for which his institution (Department of Pediatric Gastroenterology and Hepatology, University Medical Center Groningen, The Netherlands) is compensated financially. The previous position of N. v. V. was partly funded by Danone Research, but she has currently no affiliation with Danone Research and therefore no conflict of interest.

The authors' contributions are as follows: A. O., D. K., M. A.-B. and E. M. v. d. B. designed the research; A. O., L. S., N. v. V. and D. K. conducted the research; S. R. provided essential materials; A. O., N. V. V., L. S., S. R. and D. K. analysed the data, A. O. wrote the paper, H. J. V. reviewed the manuscript, E. M. v. d. B. had primary responsibility for the final content. All authors read and approved the final manuscript.

\section{References}

1. Budge H, Sebert S, Sharkey D, et al. (2009) Session on 'obesity'. Adipose tissue development, nutrition in early life and its impact on later obesity. Proc Nutr Soc 68, 321-326. 
2. Knittle JL, Timmers K, Ginsberg-Fellner F, et al. (1979) The growth of adipose tissue in children and adolescents. Cross-sectional and longitudinal studies of adipose cell number and size. J Clin Invest 63, 239-246.

3. Spalding KL, Arner E, Westermark PO, et al. (2008) Dynamics of fat cell turnover in humans. Nature $\mathbf{4 5 3}$, $783-787$.

4. Gruen R, Kava R \& Greenwood MR (1980) Development of basal lipolysis and fat cell size in the epididymal fat pad of normal rats. Metabolism 29, 246-253.

5. Hubbard RW \& Matthew WT (1971) Growth and lipolysis of rat adipose tissue: effect of age, body weight, and food intake. J Lipid Res 12, 286-293.

6. Greenwood MR \& Hirsch J (1974) Postnatal development of adipocyte cellularity in the normal rat. J Lipid Res $\mathbf{1 5}$, $474-483$.

7. Hemmeryckx B, Loeckx D, Dresselaers T, et al. (2010) Age-associated adaptations in murine adipose tissues. Endocr J 57, 925-930.

8. Obst BE, Schemmel RA, Czajka-Narins D, et al. (1981) Adipocyte size and number in dietary obesity resistant and susceptible rats. Am J Physiol 240, E47-E53.

9. Bourgeois F, Alexiu A \& Lemonnier D (1983) Dietary-induced obesity: effect of dietary fats on adipose tissue cellularity in mice. BrJ Nutr 49, 17-26.

10. DiGirolamo M, Fine JB, Tagra K, et al. (1998) Qualitative regional differences in adipose tissue growth and cellularity in male Wistar rats fed ad libitum. Am J Physiol 274, R1460-R1467.

11. Darlington GJ, Ross SE \& MacDougald OA (1998) The role of C/EBP genes in adipocyte differentiation. J Biol Chem 273, 30057-30060.

12. Berger J \& Moller DE (2002) The mechanisms of action of PPARs. Annu Rev Med 53, 409-435.

13. Rosen ED, Sarraf P, Troy AE, et al. (1999) PPAR gamma is required for the differentiation of adipose tissue in vivo and in vitro. Mol Cell 4, 611-617.

14. Tamori Y, Masugi J, Nishino N, et al. (2002) Role of peroxisome proliferator-activated receptor-gamma in maintenance of the characteristics of mature 3T3-L1 adipocytes. Diabetes 51, 2045-2055.

15. Waku T, Shiraki T, Oyama T, et al. (2009) Structural insight into PPAR gamma activation through covalent modification with endogenous fatty acids. J Mol Biol 385, 188-199.

16. Desai M, Guang H, Ferelli M, et al. (2008) Programmed upregulation of adipogenic transcription factors in intrauterine growth-restricted offspring. Reprod Sci 15, 785-796.

17. Desai M \& Ross MG (2011) Fetal programming of adipose tissue: effects of intrauterine growth restriction and maternal obesity/high-fat diet. Semin Reprod Med 29, 237-245.

18. Verier C, Meirhaeghe A, Bokor S, et al. (2010) Breast-feeding modulates the influence of the peroxisome proliferatoractivated receptor-gamma (PPARG2) Pro12Ala polymorphism on adiposity in adolescents: The Healthy Lifestyle in Europe by Nutrition in Adolescence (HELENA) cross-sectional study. Diabetes Care 33, 190-196.

19. Agostoni C (2005) Ghrelin, leptin and the neurometabolic axis of breastfed and formula-fed infants. Acta Paediatr 94, 523-525.

20. Michalski MC (2007) On the supposed influence of milk homogenization on the risk of CVD, diabetes and allergy. Br J Nutr 97, 598-610.

21. Oosting A, Kegler D, Wopereis HJ, et al. (2012) Size and phospholipid coating of lipid droplets in the diet of young mice modify body fat accumulation in adulthood. Pediatr Res 72, 362-369.
22. van Baalen A, van der Beek E, Beermann C, et al. (2010) Nutritional Compositions with Lipid Globules with a Core Comprising Vegetable Lipids and a Coating Comprising Phospholipids or Polar Lipids [NV NUTRICIA, editor]. WO patent: NUTRICIA, N.V.

23. Reeves PG, Nielsen FH \& Fahey GC (1993) AIN-93 purified diets for laboratory rodents: final report of the American Institute of Nutrition ad boc writing committee on the reformulation of the AIN-76A rodent diet. J Nutr 123, 1939-1951.

24. Golde WT, Gollobin P \& Rodriguez LL (2005) A rapid, simple, and humane method for submandibular bleeding of mice using a lancet. Lab Anim (NY) 34, 39-43.

25. Di Girolamo M \& Fine JB (2001) Cellularity measurements. Methods Mol Biol 155, 65-75.

26. Folch J, Lees M \& Sloane Stanley GH (1957) A simple method for the isolation and purification of total lipides from animal tissues. J Biol Chem 226, 497-509.

27. de Jonge HJ, Fehrmann RS, de Bont ES, et al. (2007) Evidence based selection of housekeeping genes. PLOS One 2, e898.

28. Knittle JL \& Hirsch J (1968) Effect of early nutrition on the development of rat epididymal fat pads: cellularity and metabolism. J Clin Invest 47, 2091-2098.

29. Wahlen K, Sjolin E \& Lofgren P (2011) Role of fat cell size for plasma leptin in a large population based sample. Exp Clin Endocrinol Diabetes 119, 291-294.

30. Eberle D, Hegarty B, Bossard P, et al. (2004) SREBP transcription factors: master regulators of lipid homeostasis. Biochimie 86, 839-848.

31. Palou M, Priego T, Sanchez J, et al. (2008) Sequential changes in the expression of genes involved in lipid metabolism in adipose tissue and liver in response to fasting. Pflugers Arch 456, 825-836.

32. Morgan K, Uyuni A, Nandgiri G, et al. (2008) Altered expression of transcription factors and genes regulating lipogenesis in liver and adipose tissue of mice with high fat diet-induced obesity and nonalcoholic fatty liver disease. Eur J Gastroenterol Hepatol 20, 843-854.

33. Palou M, Sanchez J, Priego T, et al. (2010) Regional differences in the expression of genes involved in lipid metabolism in adipose tissue in response to short- and medium-term fasting and refeeding. $J$ Nutr Biochem 21, $23-33$.

34. Kersten S (2001) Mechanisms of nutritional and hormonal regulation of lipogenesis. EMBO Rep 2, 282-286.

35. de Heredia FP, Larque E, Del Puy Portillo M, et al. (2008) Age-related changes in fatty acids from different adipose depots in rat and their association with adiposity and insulin. Nutrition 24, 1013-1022.

36. Guo KY, Halo P, Leibel RL, et al. (2004) Effects of obesity on the relationship of leptin mRNA expression and adipocyte size in anatomically distinct fat depots in mice. Am J Physiol Regul Integr Comp Physiol 287, R112-R119.

37. Drolet R, Richard C, Sniderman AD, et al. (2008) Hypertrophy and hyperplasia of abdominal adipose tissues in women. Int J Obes (Lond) 32, 283-291.

38. Muhlhausler BS, Cook-Johnson R, James M, et al. (2010) Opposing effects of omega-3 and omega- 6 long chain polyunsaturated fatty acids on the expression of lipogenic genes in omental and retroperitoneal adipose depots in the rat. J Nutr Metab (epublication 5 August 2010).

39. van Harmelen V, Dicker A, Ryden M, et al. (2002) Increased lipolysis and decreased leptin production by human omental as compared with subcutaneous preadipocytes. Diabetes $\mathbf{5 1}$, 2029-2036. 
40. Di Girolamo M, Mendlinger S \& Fertig JW (1971) A simple method to determine fat cell size and number in four mammalian species. Am J Physiol 221, 850-858.

41. Hishikawa D, Hong YH, Roh SG, et al. (2005) Identification of genes expressed differentially in subcutaneous and visceral fat of cattle, pig, and mouse. Physiol Genomics 21, $343-350$

42. Tchernof A, Belanger C, Morisset AS, et al. (2006) Regional differences in adipose tissue metabolism in women: minor effect of obesity and body fat distribution. Diabetes $\mathbf{5 5}$, $1353-1360$.

43. Ray H, Pinteur C, Frering V, et al. (2009) Depot-specific differences in perilipin and hormone-sensitive lipase expression in lean and obese. Lipids Health Dis $\mathbf{8}, 58$.

44. Kloting N, Berthold S, Kovacs P, et al. (2009) MicroRNA expression in human omental and subcutaneous adipose tissue. PLoS One 4, e4699.

45. Durmus B, Mook-Kanamori DO, Holzhauer S, et al. (2010) Growth in foetal life and infancy is associated with abdominal adiposity at the age of 2 years: the generation $\mathrm{R}$ study. Clin Endocrinol (Oxf) 72, 633-640.

46. Ibanez L, Lopez-Bermejo A, Diaz M, et al. (2011) Catch-up growth in girls born small for gestational age precedes childhood progression to high adiposity. Fertil Steril 96, 220-223.

47. Wells JC, Haroun D, Levene D, et al. (2011) Prenatal and postnatal programming of body composition in obese children and adolescents: evidence from anthropometry, DXA and the 4-component model. Int J Obes (Lond) 35, 534-540.

48. Demerath EW, Reed D, Choh AC, et al. (2009) Rapid postnatal weight gain and visceral adiposity in adulthood: the Fels Longitudinal Study. Obesity (Silver Spring) 17, 2060-2066.

49. Holzhauer S, Zwijsen RM, Jaddoe VW, et al. (2009) Sonographic assessment of abdominal fat distribution in infancy. Eur J Epidemiol 24, 521-529.

50. Cryer A \& Jones HM (1980) The development of white adipose tissue. Effect of litter size on the lipoprotein lipase activity of four adipose-tissue depots, serum immunoreactive insulin and tissue cellularity during the first year of life in male and female rats. Biochem J 186, 805-815.

51. Garcia AP, Palou M, Sanchez J, et al. (2011) Moderate caloric restriction during gestation in rats alters adipose tissue sympathetic innervation and later adiposity in offspring. PLoS One 6, e17313.

52. Vallee M, Mayo W, Maccari S, et al. (1996) Long-term effects of prenatal stress and handling on metabolic parameters: relationship to corticosterone secretion response. Brain Res 712, 287-292.

53. Young JB (2000) Effects of neonatal handling on sympathoadrenal activity and body composition in adult male rats. $\mathrm{Am}$ J Physiol Regul Integr Comp Physiol 279, R1745-R1752.

54. Faust IM, Johnson PR \& Hirsch J (1980) Long-term effects of early nutritional experience on the development of obesity in the rat. $J$ Nutr 110, 2027-2034

55. Bays HE, Gonzalez-Campoy JM, Bray GA, et al. (2008) Pathogenic potential of adipose tissue and metabolic consequences of adipocyte hypertrophy and increased visceral adiposity. Expert Rev Cardiovasc Ther 6, 343-368.

56. Chumlea WC, Siervogel RM, Roche AF, et al. (1982) Changes in adipocyte cellularity in children ten to 18 years of age. Int J Obes 6, 383-389.

57. Spiegelman BM \& Flier JS (1996) Adipogenesis and obesity: rounding out the big picture. Cell $\mathbf{8 7}, 377-389$.

58. Armand M, Hamosh M, Mehta NR, et al. (1996) Effect of human milk or formula on gastric function and fat digestion in the premature infant. Pediatr Res 40, 429-437.

59. Michalski MC, Briard V, Desage M, et al. (2005) The dispersion state of milk fat influences triglyceride metabolism in the rat - a $13 \mathrm{CO} 2$ breath test study. Eur J Nutr $\mathbf{4 4}$, 436-444.

60. Michalski MC, Soares AF, Lopez C, et al. (2006) The supramolecular structure of milk fat influences plasma triacylglycerols and fatty acid profile in the rat. Eur J Nutr $\mathbf{4 5}$, 215-224. 